\title{
Dynamic viscoelastic properties, water absorption, and solubility of home reliners
}

\author{
Hiroshi MURATA¹, Guang HONG², Chiaki YAMAKADO³ ${ }^{3}$ Tadafumi KUROGI ${ }^{1}$, Hiroshi KANO ${ }^{1}$ and Taizo HAMADA² \\ ${ }^{1}$ Department of Prosthetic Dentistry, Graduate School of Biomedical Sciences, Nagasaki University, 1-7-1 Sakamoto, Nagasaki 852-8588, Japan \\ ${ }^{2}$ Department of Oral Health Care Promotion, Graduate School of Dentistry, Tohoku University, 4-1 Seiryo-machi, Aoba-ku, Sendai 980-8575, Japan \\ ${ }^{3}$ Okamoto Dental Clinic, 312 Kodono-cho, Nara, 630-8441, Japan \\ Corresponding author, Hiroshi MURATA; E-mail: hmurata@nagasaki-u.ac.jp
}

\begin{abstract}
Scant rheological information is available regarding home reliners (liner type denture adhesives). We evaluated 6 different home reliners in regard to their viscoelastic properties, water absorption and solubility. Dynamic viscoelastic properties and changes over time were determined using a dynamic viscoelastometer, while weight changes, absorption, and solubility during immersion in water were also investigated. We found that the dynamic viscoelasticity of the tested home reliners was sensitive to changes in frequency, while the materials used had nearly no elasticity and exhibited viscous behaviors. They showed a dramatic change in viscoelastic properties and increase in weight after approximately 1 day of water immersion. A considerably high percentage of water absorption was also observed. From the viewpoint of dynamic viscoelastic properties and durability, our results indicate that the tested home reliners would not be suitable for improvement of ill-fitting dentures.
\end{abstract}

Keywords: Home reliner, Liner type denture adhesive, Dynamic viscoelasticity

\section{INTRODUCTION}

Denture adhesives and home reliners available on the retail market are widely used by many patients who wear removable partial or complete dentures to enhance the fit of the prosthesis. The number of patients using complete dentures is expected to increase over the next 20 years, despite an expected decline in the age-specific rate of edentulism, because life expectancy rates and the numbers of adults in each specific age group are increasing ${ }^{11}$. Accordingly, the use of denture adhesives and home reliners will likely spread more widely among denture users in the future.

Denture stabilizing materials ${ }^{2)}$ are classified into 2 main types; denture adhesives and home reliners ${ }^{3)}$ with denture adhesives further divided into powder, cream, and tape types. Denture adhesives function to produce a highly viscous layer between the denture intaglio surface and denture-bearing mucosa by absorbing saliva ${ }^{4}$, resulting in increases in stability and retention of ill-fitting dentures. On the other hand, home reliners are confined to the cushion type, and their materials are designed to fill the gap between an ill-fitting denture and mucosa to enhance the fit. Previous studies investigated the effects of the denture adhesives on viscosity ${ }^{4}$, masticatory performance ${ }^{5,6)}$ retention of dentures $^{7-9)}$, their bonding strength ${ }^{10,11}$, microbial contamination $^{12)}$ and cytotoxicity ${ }^{11,13,14)}$. Although some problems such as avoidance of necessary dental visits or the possibility of development of certain oral conditions (denture stomatitis and candidiasis) as a result of their use remain to be addressed, academic prosthodontists in the United States have concluded that cream and powder type denture adhesives are useful adjuncts in denture prosthesis services, with specific roles in both fabrication and post-insertion phases ${ }^{15}$. On the other hand, in the case of home reliners, only a small number of reports, including clinical observations ${ }^{16,17)}$, and studies of bonding strength $^{10)}$, microbial contamination ${ }^{18)}$ and cytotoxicity $^{13,14)}$ are available. However, there are no known reports regarding such rheological properties as viscoelasticity, which has an influence on the masticatory function of denture wearers, as well as water absorption and solubility of home reliners. Such information is necessary for patient education regarding the use of these materials.

Home reliners are supplied as a paste packed into a tube. They are soft materials and mainly comprised of polyvinyl acetate containing varying amounts of ethyl alcohol ${ }^{3,14)}$. The polyvinyl acetate is amorphous polymer. In previous studies, the viscoelastic properties of soft dental materials, including tissue conditioners and long-term soft denture liners, were characterized using creep $^{19)}$, stress relaxation ${ }^{20)}$, and dynamic mechanical ${ }^{21,22)}$ tests. Static measurements obtained from the results of creep and stress relaxation tests have provided valuable information regarding the behaviors of the materials under long-term force caused by functional pressure or changes of denture-bearing mucosa. However, dynamic mechanical test findings are more suitable for precise evaluation of those behaviors under cyclical and rapidly applied forces that reflect mastication, in addition to behavior under longterm force, as compared to static methods ${ }^{22)}$. In order to more closely simulate the clinical behavior of home reliners, it is necessary to assess their dynamic viscoelastic properties over a wide range of frequencies.

In the present study, we evaluated the dynamic viscoelastic properties of home reliners over a wide 
range of frequencies and their changes over time. In addition, water absorption and solubility of the materials were also evaluated.

\section{MATERIALS AND METHODS}

Six home reliners (liner type denture adhesives) tested are listed in Table 1, together with the code, manufacturer and general composition. According to our measurements, the inorganic component content in $\mathrm{LD}$ and $\mathrm{PA}$ is 3.0 and $1.5 \mathrm{wt} \%$, respectively. That of $\mathrm{CC}$ and $\mathrm{TH}$ is less than $0.1 \mathrm{wt} \%$. The inorganic component is not included in CS and TT.

Fifteen specimens for each material were prepared to a thickness of $2 \mathrm{~mm}$ ( $30 \mathrm{~mm}$ long $\times 20 \mathrm{~mm}$ wide) by squeezing the material from the tube into a polytetrafluoroethylene (PTFE) mould and pressing down onto the mass using 2 flat glass plates. The first 10 specimens were used for determination of dynamic viscoelastic properties and the remaining 5 for measuring weight changes.

\section{Dynamic viscoelastic properties}

The dynamic viscoelastic properties of the tested materials were determined using an automatic dynamic viscoelastometer (Rheovibron DDV-25FP, Orientec Corp., Tokyo, Japan) (Fig. 1), whose function is based on a non-resonance-forced vibration principle ${ }^{23)}$. This device consists of a measurement operation block, high/ low constant temperature chamber, main unit, power unit, data processing device and testing jigs, and measures the response of a material to a sinusoidal or other periodic stress. Five pairs of specimens from each material were stored in distilled water at $37^{\circ} \mathrm{C}$. A series of tests was conducted at $37^{\circ} \mathrm{C}$ on the specimen pairs with a shearing jig, beginning at 30 minutes after
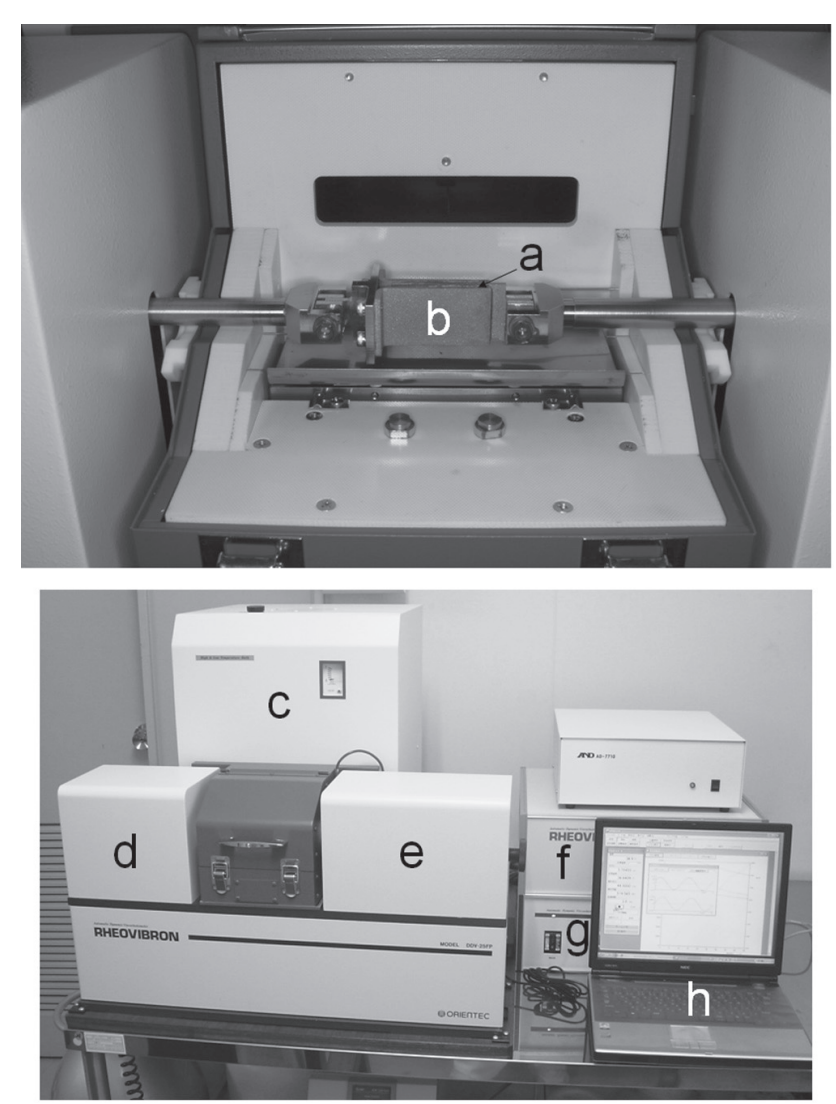

Fig. 1 Dynamic viscoelastometer. Two specimens were set in a shearing jig. (a): specimen, (b): shearing jig, (c): high/low constant temperature chamber, (d): driver and displacement detector, (e): load detector, (f): main unit, (g): power amplifier, and (h): personal computer.

Table 1 Home reliners tested

\begin{tabular}{|c|c|c|c|}
\hline Material & Code & Manufacturer & Composition* \\
\hline Cushion Correct & $\mathrm{CC}$ & $\begin{array}{l}\text { Shionogi \& Co., Ltd., Osaka, } \\
\text { Japan }\end{array}$ & Polyvinyl acetate, Ethyl alcohol \\
\hline Correct Soft A & $\mathrm{CS}$ & $\begin{array}{l}\text { Shionogi \& Co., Ltd., Osaka, } \\
\text { Japan }\end{array}$ & $\begin{array}{l}\text { Polyvinyl acetate, Ethyl alcohol, Food red no. } 2 \text {, } \\
\text { Food red no.3 Aluminum Lake, Food yellow no.5 } \\
\text { Aluminum Lake }\end{array}$ \\
\hline Liodent & $\mathrm{LD}$ & Lion Corporation, Tokyo, Japan & $\begin{array}{l}\text { Polyvinyl acetate, Ethyl alcohol, Polypropylene } \\
\text { glycol**, White beeswax, Light calcium carbonate }\end{array}$ \\
\hline Tafugurippu Tômei & $\mathrm{TT}$ & $\begin{array}{l}\text { Kobayashi Pharmaceutical Co., } \\
\text { Ltd., Osaka, Japan }\end{array}$ & $\begin{array}{l}\text { Polyvinyl acetate, Ethyl alcohol, } \\
\text { Aminoalkylmethacrylate copolymer RS }\end{array}$ \\
\hline Tafugurippu Hadairo & $\mathrm{TH}$ & $\begin{array}{l}\text { Kobayashi Pharmaceutical Co., } \\
\text { Ltd., Osaka, Japan }\end{array}$ & $\begin{array}{l}\text { Polyvinyl acetate, Ethyl alcohol, } \\
\text { Aminoalkylmethacrylate copolymer RS }\end{array}$ \\
\hline Polident Adhesive & $\mathrm{PA}$ & $\begin{array}{l}\text { Earth Chemical Co., Ltd., Tokyo, } \\
\text { Japan } \\
\text { GlaxoSmithKline K.K., Tokyo, } \\
\text { Japan }\end{array}$ & $\begin{array}{l}\text { Polyvinyl acetate, Ethyl alcohol, Red no.225, } \\
\text { Bentonite }\end{array}$ \\
\hline
\end{tabular}

\footnotetext{
* Composition as given by manufacturers
}

** Reference 3) 
squeezing the material from the tube (no immersion in water; baseline), then after 12 hours, and 1, 2, 4, and 7 days. Using this device, sinusoidal shear strain was added to one end of a pair of specimens and stress response was detected at the other end. Amplitude attenuation of the sinusoidal strain and delay of the strain wave are dependent on the viscoelastic properties of the material ${ }^{24)}$. Complex dynamic shear modulus $\left(G^{*}\right)$, shear storage modulus $\left(G^{\prime}\right)$, shear loss modulus $\left(G^{\prime \prime}\right)$, and loss tangent $(\tan \delta)$ values were determined over a frequency range of 0.1 to $100 \mathrm{~Hz}$ with a strain of $0.7 \%$ (linear viscoelastic zone). Lissajous's figures, which showed relationship between sinusoidal strain and stress response, and the waves of strain and stress were monitored to confirm the measurement in the linear viscoelastic zone during test.

$G^{*}, G^{\prime}, G^{\prime \prime}$, and $\tan \delta$ were calculated using the following formulae ${ }^{24)}$.

$$
\begin{aligned}
& G^{*}=G^{\prime}+i G^{\prime \prime} \\
& G^{\prime}=|G *| \cos \delta \\
& G^{\prime \prime}=\left|G^{*}\right| \sin \delta \\
& \tan \delta=G^{\prime \prime} \mid G^{\prime}
\end{aligned}
$$

where $i=\sqrt{-1}$, and $\delta=$ the phase angle between stress and strain. $G^{*}$ was resolved into two components: $G^{\prime}$ and $G^{\prime \prime}$. $G^{\prime}$ demonstrated elastic deformation under stress, whereas $G^{\prime \prime}$ showed viscous deformation, and $\tan \delta$ provided an indication of the relative contribution of the elastic and viscous components that accounted for the overall behavior of each of the tested materials.

\section{Weight changes, absorption, and solubility}

Weight changes, absorption, and solubility of the home reliners during immersion in distilled water were examined according to methods previously described ${ }^{25)}$. Five specimens from each tested material were measured. Specimens were weighed to an accuracy of $0.0001 \mathrm{~g}$ using an analytical balances (AW220, Shimadzu Corp., Kyoto, Japan) at 30 minutes after squeezing the material from the tube (no immersion in water; baseline), and were then immersed in the distilled water at $37^{\circ} \mathrm{C}$. The specimens were removed from the distilled water, blotted dry, and reweighed at 12 hours, and 1, 2, 4, and 7 days after preparation. The weight changes of the home reliners over time were expressed as percentages using the following formula:

Weight change $(\%)=\left(W-W_{1}\right) \times 100 / W_{1}$

where $W$ is the weight of the home reliner and $W_{1}$ the initial weight of the home reliner before immersion in water (30 minutes after specimen preparation).

The percentages of absorption and solubility of the home reliners after 7 days of water immersion were determined as follows:

Absorption $(\%)=\left(W_{2}-W_{3}\right) \times 100 / W_{1}$

Solubility $(\%)=\left(W_{1}-W_{3}\right) \times 100 / W_{1}$ where $W_{2}$ is the weight after absorption and desorption and $W_{3}$ the final weight after desiccation. The specimens were dried in a desiccator containing silica gel until a constant weight $( \pm 0.5 \mathrm{mg})$ was obtained.

\section{Statistical analyses}

A frequency value of $1 \mathrm{~Hz}$ was selected as the baseline for statistical analyses. Two-way analyses of variance (ANOVA) were performed to determine whether statistically significant differences were present between the materials and immersion times for the rheological parameters $\left(G^{\prime}, G^{\prime \prime}\right.$, and $\tan \delta$ ) and percent weight change. The differences among the materials and those among immersion times were tested with a Student-Newman-Keuls test, with a $5 \%$ level of significance. Comparisons of the percentages of absorption and solubility were subjected to one-way ANOVA combined with a Student-Newman-Keuls test, with a $5 \%$ level of significance. A t-test was also conducted to determine whether statistically significant differences existed between $G^{\prime}$ and $G^{\prime \prime}$, and between the percent absorption and percent solubility values.

\section{RESULTS}

Figure 2 shows the frequency dependence for storage modulus $\left(G^{\prime}\right)$, loss modulus $\left(G^{\prime \prime}\right)$, and loss tangent (tan $\delta$ ) for the 6 tested home reliners before immersion in water (30 minutes after squeezing the material from the tube). All of the home reliners exhibited greater values for $G^{\prime}$ and $G^{\prime \prime}$ at higher frequencies, whereas the $\tan \delta$ of all, especially TT and TH, decreased as the frequency increased. $G^{\prime}, G^{\prime \prime}$, and $\tan \delta$ of the 6 home reliners at $1 \mathrm{~Hz}$ before immersion in water are illustrated in Figure 3. Values of $G^{\prime}$ were significantly higher $(p<0.01)$ than those of $G^{\prime \prime}$ for CC, CS, and PA, whereas the values of $G^{\prime \prime}$ were significantly higher $(p<0.01)$ than those of $G^{\prime}$ for LD, TT, and TH. PA had the highest $G^{\prime}$ value among the home reliners tested. In addition, the values of $G^{\prime}$ for $\mathrm{CC}, \mathrm{CS}, \mathrm{TT}$, and $\mathrm{TH}$ were significantly lower $(p<0.05)$ than those of the other 2 materials, with no significant differences found among those 4. PA had the highest value for $G^{\prime \prime}$ and CS the lowest. The order of $G^{\prime \prime}$ values for the home reliners were $\mathrm{PA}>\mathrm{LD}>\mathrm{TH}>\mathrm{TT}, \quad \mathrm{CC}>\mathrm{CS} \quad(p<0.05)$. The highest $\tan \delta$ value was noted for TT, and the $\tan \delta$ values for $\mathrm{TT}, \mathrm{TH}$, and LD were greater than 1.0. No significant differences were found among $\mathrm{CC}, \mathrm{CS}$, and PA for $\tan \delta$ values, which were less than 1.0 and significantly lower $(p<0.05)$ than those of the other materials.

The variations of $G^{\prime}, G^{\prime \prime}$, and $\tan \delta$ over time of water immersion for the 6 tested home reliners at $1 \mathrm{~Hz}$ are shown in Figure 4. Two-way ANOVA results indicated significant differences among the home reliners and significant effects of immersion time for the 3 rheological parameters $(p<0.0005)$. The $G^{\prime}$ and $G^{\prime \prime}$ values for all the materials, especially $\mathrm{LD}, \mathrm{TT}$, and $\mathrm{TH}$, tended to increase rapidly until 1 or 2 days of immersion, after which the changes were gradual or nearly halted up to 7 days. In contrast, the $\tan \delta$ values 

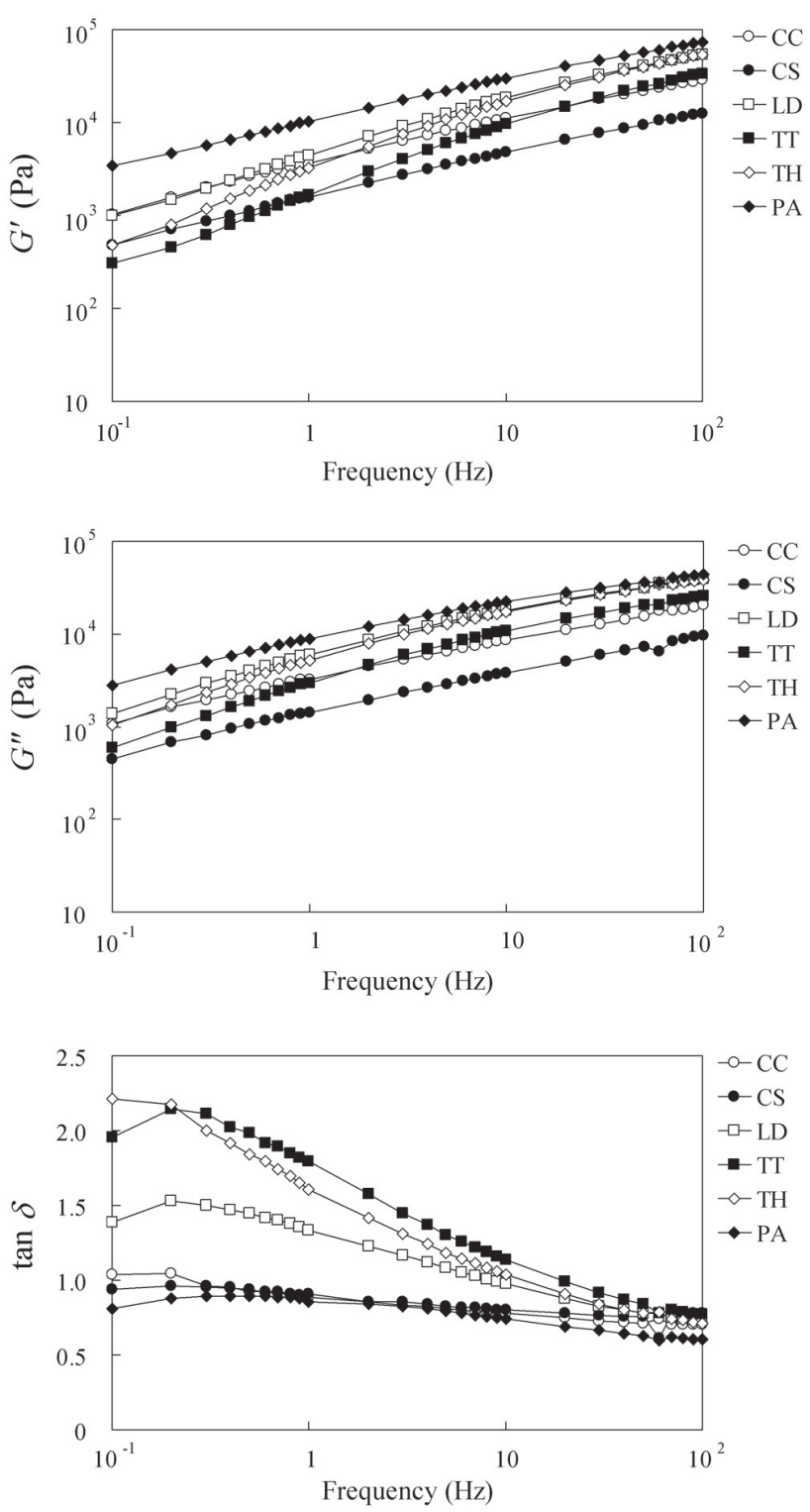

Fig. 2 Variations of storage modulus $\left(G^{\prime}\right)$, loss modulus $\left(G^{\prime \prime}\right)$, and loss tangent $(\tan \delta)$ values with frequency for 6 home reliners before immersion in water (30 minutes after squeezing material from tube).

of all home reliners, especially LD, TT, and TH, decreased rapidly until 12 hours and then gradually increased until 7 days.

Figure 5 shows weight changes over time of water immersion for the 6 tested home reliners. All demonstrated a marked increase in weight over 1 or 2 days. Subsequently, the materials except for CS gradually increased up to 7 days, while CS exhibited almost no change in weight.

The absorption and solubility percentages of the home reliners following immersion in water for up to 7 days are shown in Figures 6 and 7, respectively. The
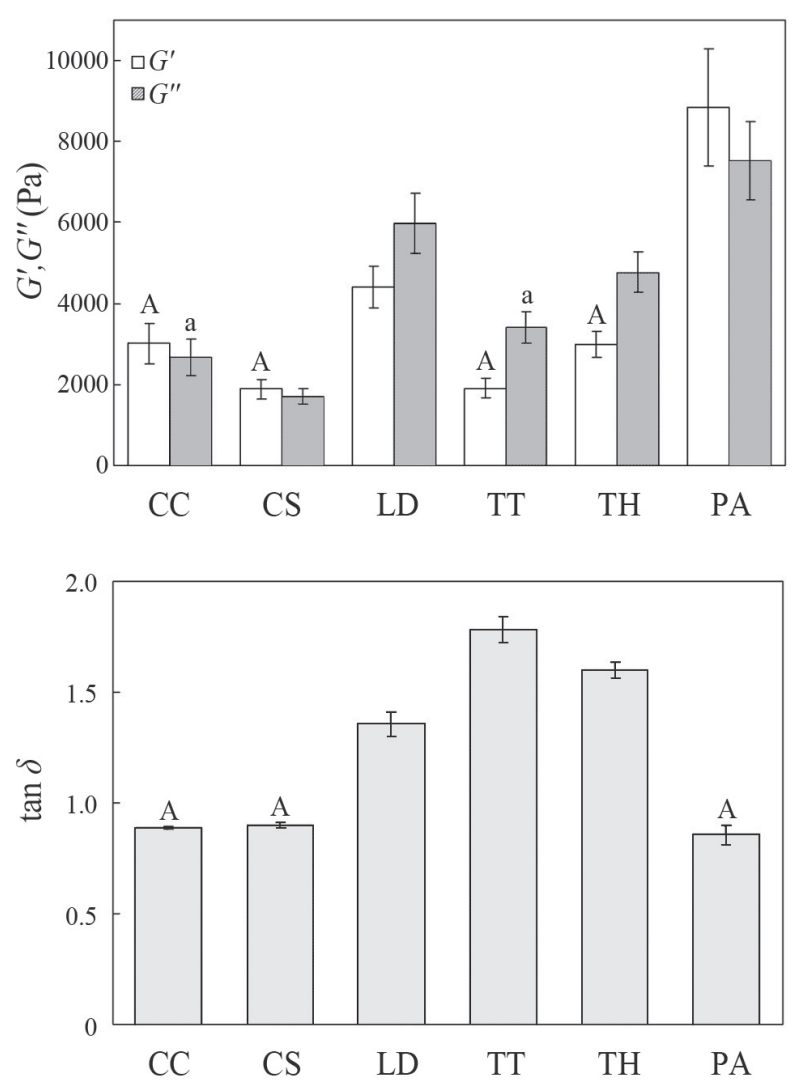

Fig. 3 Storage modulus $\left(G^{\prime}\right)$, loss modulus $\left(G^{\prime \prime}\right)$, and loss tangent $(\tan \delta)$ values for 6 home reliners at $1 \mathrm{~Hz}$ before immersion in water (30 minutes after squeezing material from tube). Identical letters indicate no statistical differences.

highest absorption percentage was recorded for TT (85.1\%) and the lowest for CS (47.8\%). The order of percent absorption was as follows: TT $>$ TH, PA>CC, $\mathrm{LD}>\mathrm{CS}(p<0.05)$. As for solubility, PA had the highest percentage (44.4\%) and CC the lowest (19.2\%). The order of percent solubility was as follows: $\mathrm{PA}>\mathrm{CS}, \mathrm{LD}$, $\mathrm{TT}>\mathrm{TH}>\mathrm{CC}(p<0.05)$. The absorption percentage values for all of the home reliners were significantly higher than their percent solubility values $(p<0.01)$.

\section{DISCUSSION}

The viscoelastic properties of home reliners (liner type denture adhesives) are important for evaluating their physical properties, which are closely related to masticatory function, adaptation between the denture intaglio surface and denture-bearing mucosa, and upkeep of optimum thickness of the layer. Measurement of viscoelastic properties of polymeric materials is generally conducted by means of static tests or dynamic test. The static tests include the creep test, which measures strains caused by a definite load in a certain range of time, and the stress relaxation test, which 

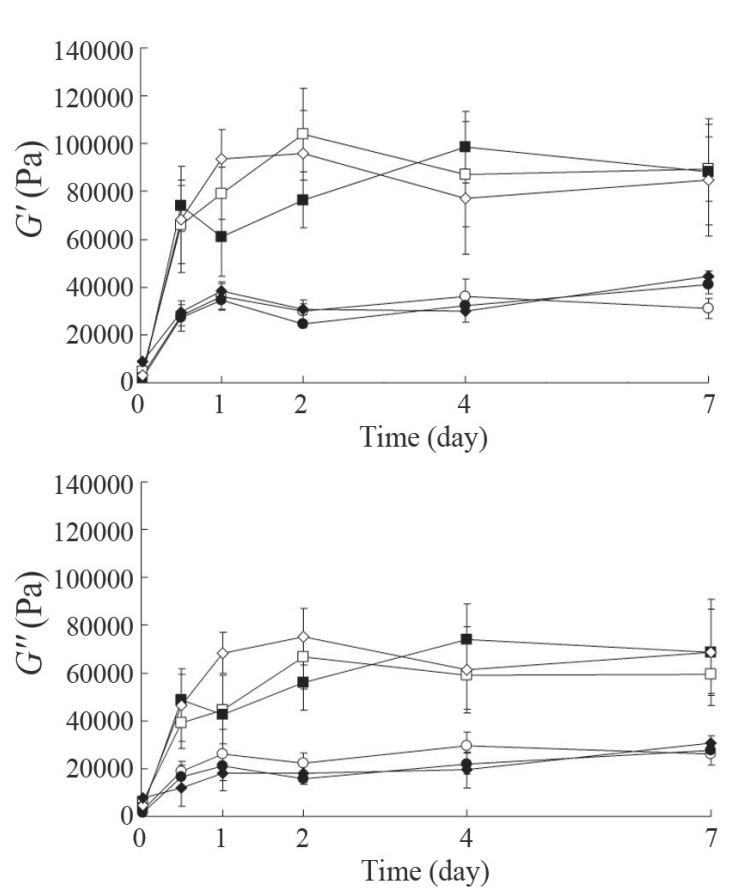

$-0-\mathrm{CC}$

$\rightarrow \mathrm{CS}$

$-\square-\mathrm{LD}$

- TT

$\rightarrow$ TH

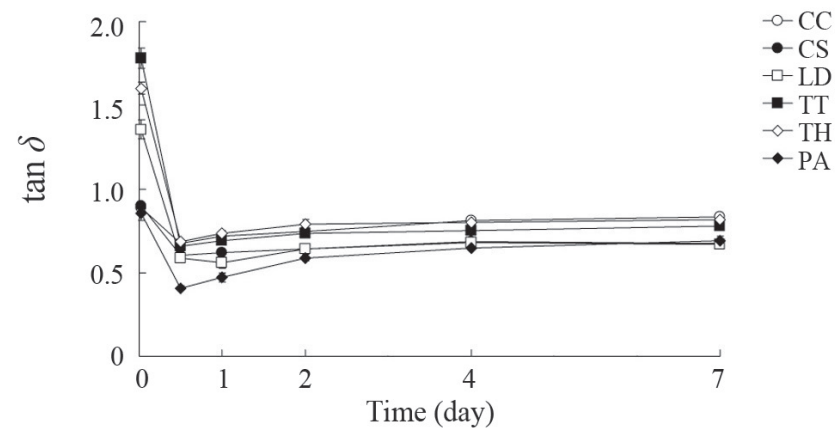

Fig. 4 Variations of storage modulus $\left(G^{\prime}\right)$, loss modulus $\left(G^{\prime \prime}\right)$, and loss tangent $(\tan \delta)$ values with time of immersion in water for 6 home reliners at $1 \mathrm{~Hz}$.

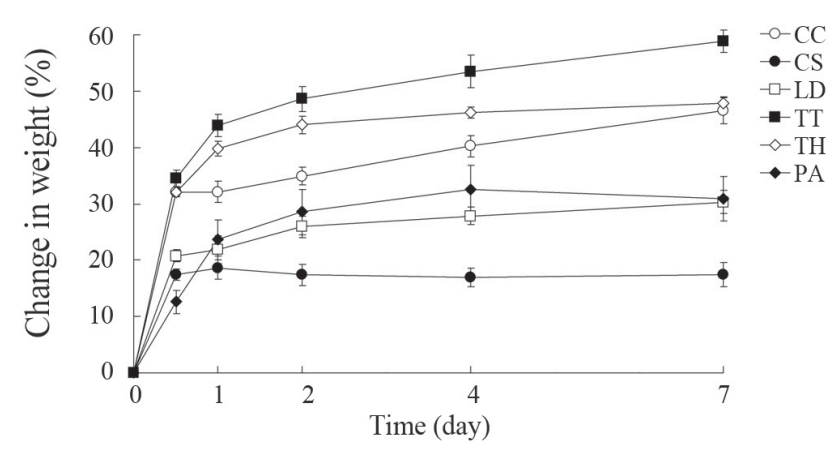

Fig. 5 Percentage changes in weight for 6 home reliners over time in water.

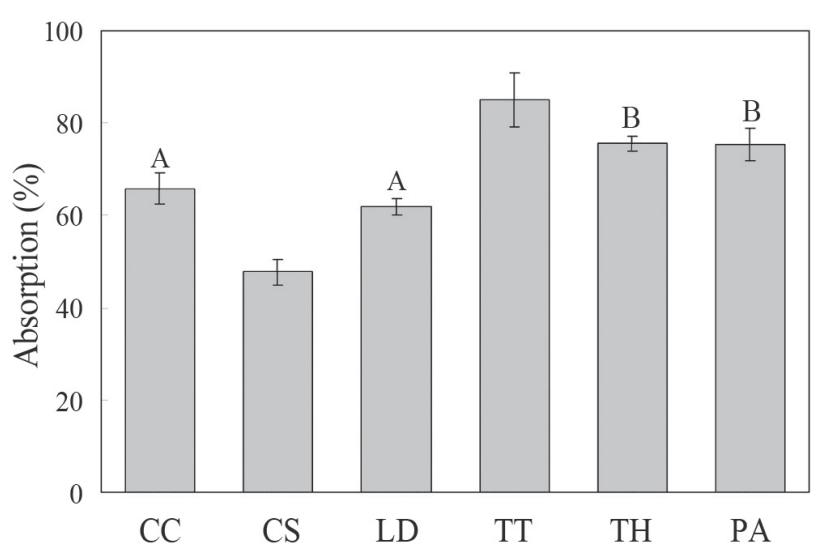

Fig. 6 Percent absorption for 6 home reliners immersed in water for 7 days. Identical letters indicate no statistical differences.

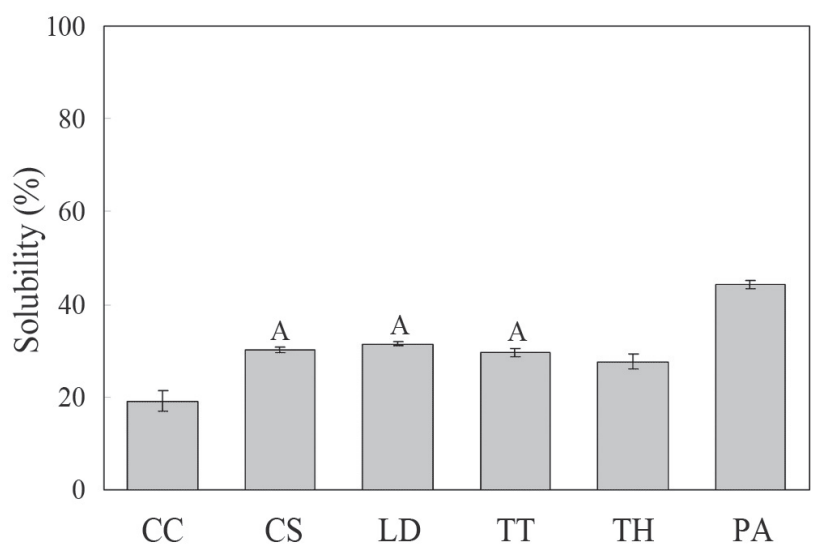

Fig. 7 Percent solubility for 6 home reliners immersed in water for 7 days. An identical letter indicates no statistical differences.

measures the stress required to maintain the level of strain as a function of time after rapidly deforming a specific volume of the test piece. Relatively simple equipment can be used for the static measurements. The information obtained from these static measurements is of interest in any application where the material must sustain load for long periods because the tests is of relatively long duration. However, in clinical situations, the home reliners used with dentures are subjected to instantaneous and cyclic stress by mastication. These static tests are not suitable for the detection of less than several seconds of material behavior ${ }^{26)}$. Measurement of the material response to the instantaneous and cyclic pressure is needed in addition to that to the continuous weak pressure to evaluate the clinical performance more precisely. On the other hand, the dynamic mechanical test based on non-resonance-forced vibration method, 
which measures the response of the material to sinusoidal or other cyclic stress, is well suited to evaluate such situations. The dynamic test is especially sensitive to the chemical and physical structure of polymeric materials and gives more information about a material than other tests ${ }^{26)}$. Dynamic mechanical analysis over a wide range of frequencies is generally possible. A periodic experiment at frequency $\omega$ is qualitatively equivalent to a transient experiment at $t=1 / \omega$. Therefore, in the present study, we determined the frequency dependence of dynamic viscoelasticity of the home reliners in order to evaluate their behaviors under mastication and functional pressure in clinical situations. Conditions associated with mastication and exposure to continuous weak pressure caused by functional pressure are reflected by a frequency value of $1 \mathrm{~Hz}$ and lower frequency value, respectively ${ }^{22)}$. We consider that rheological parameters at $1 \mathrm{~Hz}$ are most important among the frequencies tested to assess the behaviors of the materials because the cushioning effects against the mastication are determined by the viscoelastic properties at cyclic rhythm of $1 \mathrm{~Hz}$.

Large differences in dynamic viscoelastic properties were found among the tested home reliners. The dynamic viscoelasticity of all of the materials, especially $\mathrm{TH}, \mathrm{TT}$, and $\mathrm{LD}$, was sensitive to changes in frequency. The initial storage modulus $\left(G^{\prime}\right)$, loss modulus $\left(G^{\prime \prime}\right)$, and loss tangent $(\tan \delta)$ values of the home reliners at $1 \mathrm{~Hz}$ ranged from approximately 1900 to $8800 \mathrm{~Pa}, 1700$ to $7500 \mathrm{~Pa}$, and 0.86 to 1.78 , respectively. These differences among the materials were considered to be due to the differences in ethyl alcohol, polyvinyl acetate and inorganic component content. Ethyl alcohol is added to plasticize the polyvinyl acetate and adjust the viscoelastic properties as a solvent. Larger percentages of ethyl alcohol would produce the softer materials. Our results of measurement of solubility have indicated that PA would contain larger percentages of ethyl alcohol than the other materials. However, PA had the highest values of $G^{\prime}$ and $G^{\prime \prime}$ because the inorganic component (bentonite) are included in this material. The values of $G^{\prime}$ and $G^{\prime \prime}$ for $\mathrm{LD}$ were also high compared with the other materials except for PA. This is also probably due to effect of the inorganic component (light calcium carbonate). Although the inorganic components generally increase the elasticity of the polymers ${ }^{27)}$, in addition, these components are added to prevent the home reliners to stick to the fingers and improve the property of peeling off the denture intaglio surface $^{28)}$. Polypropylene glycol and white beeswax included in LD and aminoalkylmethacrylate copolymer $\mathrm{RS}$ in TT and TH are also considered to provide the function of easy peeling from the dentures and prevention of adhesion to the fingers ${ }^{28)}$. Polypropylene glycol would also decrease the grip necessary for squeezing the home reliner from tube, and white beeswax would function as plasticizer. As shown above, relationship between composition and rheological properties is complicated.

For prosthetic treatment, tissue conditioners are widely used to recondition tissues affected by ill-fitting dentures. These materials are also used to line to the denture intaglio surfaces and fashion very soft materials such as home reliners. We previously reported that the initial $G^{\prime}, G^{\prime \prime}$, and $\tan \delta$ values of tissue conditioners at $1 \mathrm{~Hz}$ ranged from approximately 35900 to $185200 \mathrm{~Pa}, 13100$ to $34600 \mathrm{~Pa}$, and 0.19 to 0.37 , respectively ${ }^{29)}$. In the present study, the $G^{\prime}$ and $G^{\prime \prime}$ values of the home reliners were extremely low, while that of $\tan \delta$ was extremely high as compared with the previously reported tissue conditioners. Our findings showed that the home reliners had nearly no elastic components and exhibited viscous behaviors.

The home reliners behaved more elastically at higher frequencies although the condition under high frequencies above $2 \mathrm{~Hz}$ would not occur in clinical situations. Clinically, a higher value of $\tan \delta$ at $1 \mathrm{~Hz}$ would indicate greater flow properties when exposed to masticatory force ${ }^{23)}$, while lower $G^{\prime}$ and $G^{\prime \prime}$ values at 1 $\mathrm{Hz}$ would show a lower ability of dentures to crush food. The rheological parameters of $0.1 \mathrm{~Hz}$ indicate behavior under continuous weak pressure by functional pressure. The materials, especially $\mathrm{TH}, \mathrm{TT}$, and LD, demonstrated higher values of $\tan \delta$ at lower frequency, and would lose the dimensional integrity of the lining with the passage of time of rest in the mouth, even though a rapid force such as mastication would not be applied. Materials with such rheological properties have a higher possibility of plastic deformation ${ }^{23)}$, causing a reduction in thickness of the layer and a reduced cushioning effect. Thus, home reliners would not produce the high masticatory efficiency of dentures.

The durability of the home reliners is another important factor for evaluation of continuous efficacy. All of the tested materials, especially TT, TH, and LD, exhibited great changes from their initial dynamic viscoelasticity over time of immersion in water; with 5to 46 -fold increases in $G^{\prime}$, 4- to 20 -fold increases in $G^{\prime \prime}$, and $6 \%$ to $56 \%$ decreases in $\tan \delta$ seen after immersion in water for 7 days, as compared with those respective values before immersion. Home reliners undergo two different processes when immersed in water, as the components of the materials are leached out into the water and water is absorbed by the materials, which likely have a large influence on their viscoelastic properties. All of the tested home reliners, especially $\mathrm{TT}$, TH, and CC, showed dramatic weight increases with immersion in water, which ranged from $17 \%$ to $59 \%$ after 7 days. Furthermore, the amounts of absorption and solubility after 7 days ranged from $47.8 \%$ to $85.1 \%$ and $19.2 \%$ to $44.4 \%$, respectively.

On the other hand, in our previous study of tissue conditioners, we found that all, except for one material with a considerably higher percentage of ethyl alcohol, exhibited weight loss of $1.6 \%$ to $7.3 \%$ during water immersion, while absorption and solubility were under $3.5 \%$, and between $4.0 \%$ and $14.0 \%$, respectively ${ }^{25)}$. The home reliners in the present study exhibited large changes in weight, and showed high solubility and considerably high absorption of water as compared with 
the tissue conditioners in that study. Although the percent absorption of water was lower than the percent solubility of the tissue conditioners, absorption by the home reliners was greater than their solubility, resulting in weight gains. Tissue conditioners generally consist of polyethyl methacrylate, ester-based plasticizer, and ethyl alcohol ${ }^{20)}$, while home reliners also contain ethyl alcohol ${ }^{3,14}$, which may leach out in a water environment. However, the taste and sensation of ethyl alcohol are generally objectionable to patients ${ }^{29)}$. Simultaneously, leaching of a larger amount of a water soluble component, i.e., ethyl alcohol, within the polymer would lead to a greater amount of water uptake $^{30)}$. It has been reported that when water permeates a water soluble component site a solution droplet is formed, which grows until osmotic and elastic forces come into balance, resulting in continuous water absorption for a long period ${ }^{30)}$. The ethyl alcohol content in home reliners would be between approximately $20 \%$ and $40 \%$ according to our results, and considerably higher than in tissue conditioners. In addition, their water absorption and the solubility of their components cause dimensional changes, surface roughening and loss of initial viscoelasticity. When home reliners change to manifest such unfavorable conditions, they can cause injury to denture-bearing mucosa and produce masticatory pain.

The results of the present study demonstrated that home reliners would have a strong tendency to flow out from the denture intaglio surface during mastication due to their highly viscous properties just after the application and that the deterioration would occur within approximately 1 day after application in the mouth. From the standpoint of viscoelastic properties and durability, the present home reliners are not considered suitable for use in improving denture function. It is considered that the materials lined in the dentures should ideally have higher values of $G^{\prime}$ and $G^{\prime \prime}$ and lower $\tan \delta$ value than the present home reliners to prevent the flow from the denture and improve masticatory efficiency. Furthermore, ethyl alcohol content in the home reliners should be reduced to prevent the deterioration in the physical properties. However, the present materials could be applied to the temporary reline of dentures of bedridden old men until dental visits. The viscoelastic properties of the present home reliners are not observed with other dental materials. Thus, other clinical applications such as protrusion of labial flange for removal of the wrinkles of the upper lip may be possible because the softness of the materials would be adequate to these purposes.

We consider that information provided by the present study will contribute to patient education. The home reliners were found to have too large flow properties just after application in the mouth and decrease in the lining thickness, resulting in a lowering of cushioning effect. Furthermore, the materials would deteriorate in viscoelastic properties and become hard within approximately 1 day after application, thereby leading to uneven stress distribution in the denture- bearing mucosa and great bonding strength to denture base acrylic resins. It is difficult for elderly users to fully remove the lining from the dentures for replacement in this situation, indicating a possible risk of reapplying the new home reliner onto remaining material. These would cause an unbalanced occlusion and resorption of residual ridge. Although the home reliners may fill the gap between an ill-fitting denture and denture-bearing mucosa, the denture liners are generally applied in dental clinic for this purpose. Dentists should not recommend the denture patients to apply the home reliners when the retention of their dentures is reduced due to the changes of residual ridge, and should instruct them to see the dentists as soon as possible.

\section{CONCLUSION}

Within the limitations of this study, we made the following conclusions.

1. The dynamic viscoelasticity of the tested home reliners (liner type denture adhesives) was sensitive to changes in frequency.

2. The home reliners had nearly no elastic components and behaved in a viscous manner. They also would show large amounts of plastic deformation under a rest condition in the mouth.

3. The dynamic viscoelastic properties of the home reliners changed dramatically after approximately 1 day of water immersion.

4. The home reliners exhibited high solubility and considerably high absorption during water immersion.

5. The present home reliners would not be suitable for improvement of function of ill-fitting dentures.

\section{ACKNOWLEDGMENTS}

This research was supported in part by a grant-in-aid for Scientific Research from the Ministry of Education, Culture, Sports, Science and Technology, Japan (no. 20390491), and a grant-in-aid for Project Research from Japanese Association for Dental Science (no. 2009C-2).

\section{REFERENCES}

1) Douglass CW, Shih A, Ostry L. Will there be a need for complete dentures in the United States in 2020? J Prosthet Dent 2002; 87: 5-8.

2) The Japanese Society for Dental Materials and Devices. A glossary for dental materials and devices. Tokyo: Ishiyaku Publishers Inc; 2005. p. 20.

3) Takahashi H. Type and characteristics of denture adhesives. J Jpn Prosthodont Soc 2003; 47: 474-483.

4) Ellis B, Al-Nakash S, Lamb DJ. The composition and rheology of denture adhesives. J Dent 1980; 8: 109-118.

5) Neill DJ, Roberts BJ. The effect of denture fixatives on masticatory performance in complete denture patients. J Dent 1973; 1: 219-222.

6) Fujimori T, Hirano S, Hayakawa I. Effects of a denture adhesive on masticatory functions for complete denture 
wearers. J Med Dent Sci 2003; 50: 239-247.

7) Ghani F, Picton DC. Some clinical investigations on retention forces of maxillary complete dentures with the use of denture fixatives. J Oral Rehabil 1994; 21: 631-640.

8) Grasso JE, Rendell J, Gay T. Effect of denture adhesive on the retention and stability of maxillary dentures. J Prosthet Dent 1994; 72: 399-405.

9) Pradíes G, Sanz I, Evans O, Martnez F, Sanz M. Clinical study comparing the efficacy of two denture adhesives in complete denture patients. Int J Prosthodont 2009; 22: 361367.

10) Fujimori T, Nakano F, Takahashi H, Iwasaki N, Nishimura F, Hayakawa I. Effects of adherend on retentive force using denture adhesives and home-reliners. J J Dent Mater 2002; 21: 368-375.

11) Zhao K, Cheng XR, Chao YL, Li ZA, Han GL. Laboratory evaluation of a new denture adhesive. Dent Mater 2004; 20: 419-424.

12) Gates WD, Goldschmidt M, Kramer D. Microbial contamination in four commercially available denture adhesives. J Prosthet Dent 1994; 71: 154-158.

13) Kakiuchi H, Imai K. In vitro cytotoxicity of denture adhesives. J J Dent Mater 1990; 9: 146-158.

14) Makihira $S$, Nikawa $H$, Nishimura $H$, Nishimura M, Murata H, Sadamori S, Ishida K, Yamashiro H, Jin C, Egusa H, Fukushima H, Hamada T. Effects of eluates of denture adhesives on human gingival fibroblasts. J Jpn Prosthodont Soc 2001; 45: 403-411.

15) Slaughter A, Katz RV, Grasso JE. Professional attitudes toward denture adhesives: A Delphi Technique survey of academic prosthodontists. J Prosthet Dent 1999; 82: 80-89.

16) Woelfel JB, Berg T, Mann AW, Kreider JA. Documented reports of bone loss caused by use of a denture reliner. JADA 1965; 71: 23-34.

17) Woelfel JB, Kreider JA. Home reliner ruins dentures and causes shrinkage. J Prosthet Dent 1968; 20: 319-325.

18) Makihira S, Nikawa H, Satonobu SV, Jin C, Hamada T.
Growth of Candida species on commercial denture adhesives in vitro. Int J Prosthodont 2001; 14: 48-52.

19) Niekawa K. Relations between the composition and viscoelastic properties of temporary soft lining materials. Kokubyo Gakkai Zasshi 1986; 53: 157-183.

20) Murata H, Hamada T, Djulaeha E, Nikawa H. Rheology of tissue conditioners. J Prosthet Dent 1998; 79: 188-199.

21) Fujii K, Arikawa H, Kanie T, Terao T, Tsuruda H, Itonaga A, Kadokawa A, Hamano T, Inoue K. Dynamic viscoelastic properties of denture base soft lining materials in vibrating reed method. J J Dent Mater 1993; 12: 117-122.

22) Murata H, Taguchi N, Hamada T, McCabe JF. Dynamic viscoelastic properties and the age changes of long-term soft denture liners. Biomaterials 2000; 21: 1421-1427.

23) Murata H, Taguchi N, Hamada T, Kawamura M, McCabe JF. Dynamic viscoelasticity of soft liners and masticatory function. J Dent Res 2002; 81: 123-128.

24) Ferry JD. Viscoelastic properties of polymers, 3rd ed. New York: John Wiley \& Sons Inc; 1980. p. 11-14.

25) Murata H, Kawamura M, Hamada T, Saleh S, Kresnoadi U, Toki K. Dimensional stability and weight changes of tissue conditioners. J Oral Rehabil 2001; 28: 918-923.

26) Nielsen LE, Landel RF. Mechanical properties of polymers and composites, 2nd ed. New York: Marcel Dekker Inc; 1994. p. 63-154.

27) Soma I. Filler data book for practical use, 1st ed. Tokyo: Kogyo Chosakai Publishing Inc; 2004. p. 10-13, 142-144, 177-180.

28) Hamada T, Murata H, Yuda S, Tamamoto M, Sadamori S. Denture adhesive, 1st ed. Tokyo: Dental Diamond Co; 2003. p. 33-42.

29) Murata H, Narasaki Y, Hamada T, McCabe JF. An alcoholfree tissue conditioner -A laboratory evaluation. J Dent 2006; 34: 307-315.

30) Braden M, Wright PS, Parker S. Soft lining materials -a review. Eur J Prosthodont Rest Dent 1995; 3: 163-174. 